\title{
Use of Pleural Fluid C- Reactive Protein and comparison with Light's criteria to differentiate Exudative from Transudative Pleural Effusions in Nepalese population
}

\author{
Jiwan Thapa ${ }^{1}$, Amal Basnet ${ }^{1}$, Kalyan Sapkota ${ }^{2}$, Anuja Bhandari Thapa ${ }^{3}$ \\ ${ }^{1}$ Department of Medicine, National Academy of Medical Sciences, Bir Hospital, Nepal \\ ${ }^{2}$ Department of Medicine, Bharatpur Hospital, Nepal \\ ${ }^{3}$ Department of Pathology, Institute of Medicine, Kathmandu
}

\section{ABSTRACT}

Pleural effusion is a common medical problem with diagnostic dilemma, this study was conducted to determine if CReactive Protein level in pleural fluid is a better diagnostic tool in differentiating exudative and transudative pleural effusion, to compare with parameters of modified Light's criteria and its application in Nepalese population. This was an Analytical, Cross-Sectional, Hospital Based Observational study of patients admitted at Department of Medicine, Bir Hospital during period of one year (January 2014-december 2015). A total of 86 patients with Unilateral Pleural effusion whose cause was unknown were enrolled. Diagnosis of pleural effusion was established by a detailed history, physical examination, chest radiograph, ultrasonography and CT scan in few cases. Demographic profiles like age, sex, location, occupation was recorded. Pleural fluid analysis was done for total leukocyte count, differential counts, total protein, LDH and CRP level along with simultaneous serum sample for total protein, albumin, LDH. Cases with Bilateral pleural effusions and who didn't give consent were excluded from study. Younger age groups (17-25yrs) and females were more affected. Out of 86 samples examine half of them were smokers and smoking had more association with females (58\%). Poor appetite and chest pain were the most common presenting symptoms 65(75\%) cases. Cut-off values of pleural fluid CRP level $\geq 10 \mathrm{mg} / \mathrm{dl}$ showed sensitivity of $87.60 \%$ where as in case of clinically identified transudates, 1 transudates out of 13 were misclassified as exudates. The specificity is $92.30 \%$, the positive predictive value and negative predictive values were $98.14 \%$, and $37.50 \%$ with a significant $p$ value of $<0.001$. All transudates were classified correctly as transudates by CRP level $>30 \mathrm{mg} / \mathrm{dl}$, whereas 44 exudates were misclassified as transudates. This criterion had a sensitivity, specificity, positive predictive value and negative predictive values of $100 \%, 36.23 \%, 27.87 \%$ and $100 \%$ respectively with a significant p value of $<0.001$. On evaluating the individual parameters of Light's Criteria; Pleural fluid LDH level $>2 / 3 \mathrm{rd}$ of LDH level of normal serum classified $64(74.41 \%$ ) cases of pleural effusion as exudates, this criteria had a sensitivity of $86.30 \%$, specificity of $92.30 \%$, positive predictive value of $98.43 \%$ and a negative predictive value of $54.55 \%$ with a significant $\mathrm{p}$ value of $<0.001$ and Kappa value is 0.77 . While on pleural fluid to serum LDH ratio >0.6, 59 (81.94\%) exudates were correctly classified as exudates whereas 13 (18.05\%) exudates were classified falsely as transudates. This criterion had a sensitivity, specificity, positive predictive value and negative predictive value of $81.94 \%, 92.31 \%, 98.36 \%$ and $48 \%$ respectively with a significant $p$ value of $<0.001$. The test result has similar sensitivity, specificity, positive predictive value and negative predictive value compared with Parameters of Light's criteria, hence could be applicable to our population as well, however multi centric studies with larger sample size are necessary.

Keywords: C-reactive protein, Pleural effusion, LDH, malignant pleural effusion, tubercular effusion protein.

\section{INTRODUCTION}

Pleura comprises the parietal pleura, the visceral pleura

\section{*Correspondence: Jiwan Thapa;}

email: jitha15@yahoo.com; Tel: 984776800,

Department of Medicine, Bir Hospital, Kathmandu, Nepal and the intervening pleural space. Both visceral and parietal pleural surfaces consist of a mesothelial layer and three connective tissue layers, but the visceral pleura is thicker than the parietal pleura. Together, the visceral and parietal pleural layers and the lubricating liquid in the pleural space have a combined thickness of 0.2 to 0.4 
$\mathrm{mm}$, while the width of the pleural space is 10 to 20 micrometers. Normally, the pleural spaces contain approximately $0.25 \mathrm{ml} / \mathrm{kg}$ of low protein liquid. The pleural space, under normal conditions, contains a small amount of fluid which is tightly regulated to ensure an efficient mechanical coupling between lung and chest wall [1].A pleural effusion is present when there is an excess quantity of fluid in the pleural space. Fluid enters the pleural space from the capillaries in the parietal pleura, interstitial spaces of the lungs via the visceral pleura and from the peritoneal cavity through channels in the diaphragm. It is removed via the lymphatics in the parietal pleura that absorbs 20 times more fluid than is normally formed. Excess accumulation occurs when the rate of pleural fluid formation exceeds its removal or due to blockade of lymphatics [2].

A mean pleural volume is $8.4 \mathrm{~mL}$ per hemithorax or 0.26 $\mathrm{ml}$ per kg. The Pleural space has normally 7 and $14 \mathrm{ml}$ of fluid and this amount of pleural fluid is not visible on chest radiograph. Conventional chest radiography with lateral decubitus views will show the presence and location of pleural effusion. When additional imaging is required to detect pleural effusion, to localize it, or guide thoracocentesis, Ultrasonography is the preferred technique for reasons of cost, availability and portability. When more detailed information about the pleural space (and other intrathoracic structures) is required CT is superior to USG [2].

Pleural effusion occurs in a variety of diseases. The first step in proper and adequate diagnosis of pleural effusion is correctly classifying it into exudative and transudative type. The primary reason to make this differentiation is that additional diagnostic procedures are indicated with exudative effusions to define the cause of the local disease. Pleural transudates are due either to alteration of hydrostatic and colloido-osmotic pressure in pleural capillaries, or to fluid passing from the peritoneal cavity to pleural cavity through defects in the diaphragm or lymph vessels, whereas pleural exudates are secondary to alteration of pulmonary capillary permeability or lymphatic obstruction. This categorization is useful in defining the patho-physiological mechanism and formulating a diagnostic approach to ascertain the etiologic diagnosis $[3,4]$.

The primary reason to differentiate transudates and exudates is that, most transudative effusions implies a non-inflammatory process with no pleural disease involvement and usually require no further investigations as the cause is usually obvious and therapy is often targeted to underlying heart failure, renal diseases or cirrhosis. Exudative effusions on the other hand present more of a diagnostic challenge and needs extensive diagnostic studies to determine the specific cause for further management.
Determining the cause of a pleural effusion is greatly facilitated by analysis of the pleural fluid. Thoracentesis is a simple bedside procedure that allows fluid to be rapidly sampled, visualized, examined, and quantified. Studies of pleural fluid characteristics in patients with diseases of known etiology have been used to develop criteria for separating effusions into transudates and exudates, each of which has a distinct differential diagnosis. Some diseases, such as pulmonary embolism can cause either transudative or exudative effusions.

These criteria are then used to categorize effusions of unknown etiology as transudates or exudates as the first step in determining a specific etiology. A systematic approach to analysis of the pleural fluid in conjunction with the clinical presentation should allow the clinician to diagnose the cause of an effusion in about 75 percent of patients at the first encounter [3]. Light's criteria has been universally accepted than any other criteria for differentiating transudates from exudates as a gold standard test for decades till now [4,5,6]. Light's criteria have a sensitivity and specificity of $99 \%$ and $98 \%$ but over last few years, many workers noted even Light's criteria misclassify significant percentage of the transudative pleural effusions as Exudative effusion[5,7].

Measurement of C-reactive protein (CRP) is widely used as a marker of inflammation and tissue damage [6]. Normal CRP in serum of healthy individuals is less than $10 \mathrm{mg} / \mathrm{dl}$. Blood levels of CRP are known to rise rapidly from normal baseline levels to as high as $50 \mathrm{mg} / \mathrm{dl}$ in infections and inflammations. CRP in pleural fluid $>10 \mathrm{mg} / \mathrm{dl}$ correlates more to exudative effusions and $>30 \mathrm{mg} / \mathrm{dl}$ correlates more to parapneumonic effusion with high sensitivity and specificity [8]. The determination procedure is inexpensive and does not take a lot of time. The half-life of CRP is constant; therefore, CRP level is mainly determined by the rate of production. This single test is easy and cost effective in our settings and avoids the need for simultaneous other blood and pleural fluid examinations in differentiating transudates from exudates.

The aim of this study is to find out the variations in CRP concentrations in pleural effusions of various etiologies, to determine its usefulness in differentiating exudative from transudative pleural effusions with Light's criteria as comparison and to study its applicability in Nepalese population.

\section{METHODOLOGY}

This is an Analytical, Cross-Sectional, Hospital Based Observational study of patients admitted at Department of medicine, Bir hospital during period of one year (January 2014-december 2015). A total of 86 patients with Unilateral Pleural Effusion whose cause was unknown were enrolled. Diagnosis of pleural effusion 
was established by a detailed history and physical examination, chest radiograph, ultrasonography and Computed Tomography scan chest where applicable. The patients were categorized into different groups based on clinical diagnosis (i.e., etiological diagnosis) as follows (1) Pleural effusions due to congestive cardiac failure (2) Tubercular pleural effusion (3) Parapneumonic pleural effusions (4) Malignant pleural effusion (5) Effusion due to Cirrhosis (6) Effusion of unclear and combined etiologies. Clinically, pleural effusion associated with congestive cardiac failure and liver cirrhosis was considered transudates and all other effusions were considered exudates. Modified Light's criteria for distinguishing between pleural exudates and transudates was applied (fluid is an exudate if one or more of the following criteria are met) Pleural fluid protein to serum protein ratio greater than 0.5 , Pleural fluid Lactate dehydrogenase ( $\mathrm{LDH})$ to serum $\mathrm{LDH}$ ratio greater than 0.6, Pleural fluid LDH greater than two thirds of the upper limit of normal for the serum $\mathrm{LDH}[5,7]$.Those patients with unilateral pleural effusion underwent thoracentesis. $10 \mathrm{ml}$ of pleural fluid was obtained by a disposable plastic syringe maintaining all aseptic precautions in inpatient settings or at emergency. The plain sample of pleural fluid thus obtained was sent immediately to the laboratory for analysis. If analysis of these samples was not feasible immediately, it was refrigerated till analysis was done within 24 hours of sample collection. The pleural fluid was analyzed for total cells, differential cell counts, total protein, LDH and CRP level along with simultaneous serum sample for total protein, albumin, Stastistical analysis was done using SPSS 16.0.

\section{RESULTS}

A total of 86 patients aged 17-88yrs with unilateral pleural effusion were enrolled in this study. Out of them 42(49\%) patients were males and 44 females (51\%), maximum males (13) in age group 15- 25 years and (9) females in age group 35- 45 years and 65- 75 years. Maximum patients were from age group 15-25 years 17 (19.76\%). 50\% patients were smokers, which was comparatively higher 25 (58.14\%) in female's $\mathrm{v}_{\mathrm{s}}$ males $18(41.86 \%)$.

Poor appetite and chest pain were the most common presenting symptoms 65(75\%) cases, other common symptoms include Dyspnea (62.8\%) and Cough (57.0\%). Edema was the least common presenting symptom $14(16.3 \%)$, the most frequent symptom in males was chest pain $52(81 \%)$ and fever $22(50 \%)$ in females as shown in table 1.

Tuberculosis was found to be the main etiological agent for pleural effusion 43 (50.0\%) in total and males 26 Table 1: Major presenting symptoms of the study
(60.4\%) followed by malignancy $17(19.8 \%)$ while hepatic hydrothorax was the least common causative agent for pleural effusion $1(1.2 \%)$, malignant pleural effusion in females was the commonest cause of pleural effusion 11(25.0\%). Details are shown in the table 2.

On the basis of clinical classification, among the 86 pleural effusion samples studied in this study, 73(85\%) pleural effusion were exudates and $13(15 \%)$ pleural effusion samples were transudates. On evaluating modified Light's Criteria; Pleural fluid LDH level $>2 / 3^{\text {rd }}$ of LDH level of normal serum classified 64(74.41\%) cases of pleural effusion as exudates, this criteria had a sensitivity of $86.30 \%$, specificity of $92.30 \%$, positive predictive value of $98.43 \%$ and a negative predictive value of $54.55 \%$ with a significant $p$ value of $<0.001$ and Kappa value is 0.77 . While on pleural fluid to serum $\mathrm{LDH}$ ratio >0.6, 59 (81.94\%) exudates were correctly classified as exudates whereas 13 (18.05\%) exudates were classified falsely as transudates. This criterion had a sensitivity, specificity, positive predictive value and negative predictive value of $81.94 \%$, 92.31\%, 98.36\% and $48 \%$ respectively with a significant $\mathrm{p}$ value of $<0.001$. Kappa value is 0.63 . The ratio of pleural protein to serum protein more than 0.5 for exudates classified 78 (90.69\%) effusions as exudates, this criterion had a sensitivity, specificity, positive predictive value and negative predictive values of $100 \%, 57.14 \%, 92.30 \%$ and $100 \%$ respectively with a significant $p$ value of $<0.001$. Kappa value is 0.69 . Details shown on table 3.

Cut-off values of CRP level $\geq 10 \mathrm{mg} / \mathrm{dl}$ showed sensitivity of $87.60 \% 64$ of 73 exudates where as in case of clinically identified transudates, 1 transudates out of 13 were misclassified as exudates. The specificity of this test was found to be higher than the sensitivity i.e. $92.30 \%$. The positive predictive value and negative predictive values of $98.14 \%$, and $37.50 \%$ with a significant $\mathrm{p}$ value of $<0.001$. All transudates were classified correctly as transudates if cut off values of CRP level was increased (> $30 \mathrm{mg} / \mathrm{dl}$ ), whereas 44 exudates were misclassified as transudates. This criterion had a sensitivity, specificity, positive predictive value and negative predictive values of $100 \%, 36.23 \%, 27.87 \%$ and $100 \%$ respectively with a significant $\mathrm{p}$ value of $<0.001 .13$ Parapneumonic effusion studied in this study, 12 (92.31\%) were classified correctly as exudates by the criteria of CRP level $>10 \mathrm{mg} / \mathrm{dl}$, which was set as a cutoff value for discrimination of exudates and transudates. Only one Parapneumonic effusion was misclassified as transudates by this criterion. This criterion had a sensitivity values of $92.31 \%$ with a significant $\mathrm{p}$ value of $<0.001$

population. 
Table 1: Major presenting the symptom of study population.

\begin{tabular}{|c|c|c|c|c|}
\hline Symptoms & $\begin{array}{l}\text { Total } \\
\text { Sample }\end{array}$ & $\begin{array}{l}\text { Total } \\
\text { cases }\end{array}$ & Male & Female \\
\hline Fever & \multirow{8}{*}{86} & $44(51.2 \%)$ & $22(50 \%)$ & $22(50.0 \%)$ \\
\hline Chest pain & & $65(75.6 \%)$ & $52(81 \%)$ & $13(20 \%)$ \\
\hline Dyspnea & & $54(62.8 \%)$ & $28(53 \%)$ & $26(47 \%)$ \\
\hline Cough & & $49(57.0 \%)$ & $26(53 \%)$ & $23(47 \%)$ \\
\hline Hemoptysis & & $20(23.3 \%)$ & $11(55 \%)$ & $9(45 \%)$ \\
\hline $\begin{array}{l}\text { Poor } \\
\text { appetite }\end{array}$ & & $65(75.6 \%)$ & $36(55 \%)$ & $29(45 \%)$ \\
\hline Weight loss & & $28(32.6 \%)$ & $16(57 \%)$ & 12(43\%) \\
\hline Edema & & 14(16.3\%) & $3(79 \%)$ & $11(21 \%)$ \\
\hline
\end{tabular}

Table 3: Predictive values of different pleural fluid
Table 2: Etiological distribution of the study population.

\begin{tabular}{|l|l|l|l|}
\hline Etiology & Total & Male & Female \\
\hline CHF & $11(12.8 \%)$ & $1(9 \%)$ & $10(91 \%)$ \\
\hline Empyema & $2(2.3 \%)$ & $1(50 \%)$ & $1(50 \%)$ \\
\hline Hepatic hydrothorax & $1(1.2 \%)$ & $1(100 \%)$ & $0(0.0 \%)$ \\
\hline Malignant pleural effusion & $17(19.8 \%)$ & $6(35.2 \%)$ & $11(64.7 \%)$ \\
\hline Parapneumonic effusion & $13(15.1 \%)$ & $7(53.8 \%)$ & $6(46.1 \%)$ \\
\hline TB effusion & $43(50.0 \%)$ & $26(60.4 \%)$ & $17(36.9 \%)$ \\
\hline
\end{tabular}

\begin{tabular}{|l|l|l|l|l|}
\hline & Sensitivity & Specificity & Positive predictive & Negative predictive \\
value & \\
\hline PF LDH>2/3 of & $86.30 \%$ & $92.30 \%$ & $98.43 \%$ & $54.50 \%$ \\
\hline PF Serum LDH & $81.94 \%$ & $92.30 \%$ & $98.36 \%$ & $48 \%$ \\
\hline ratio $>0.6$ PF serum protein & $100 \%$ & $57.14 \%$ & $92.30 \%$ & \\
\hline ratio $>0.5$ & & & & $100 \%$ \\
\hline PF CRP $>30 \mathrm{mg} / \mathrm{dl}$ & $100 \%$ & $31.88 \%$ & $36.17 \%$ & $100 \%$ \\
\hline PF CRP $>10 \mathrm{mg} / \mathrm{dl}$ & $87.60 \%$ & & $98.14 \%$ & $37.50 \%$ \\
\hline
\end{tabular}




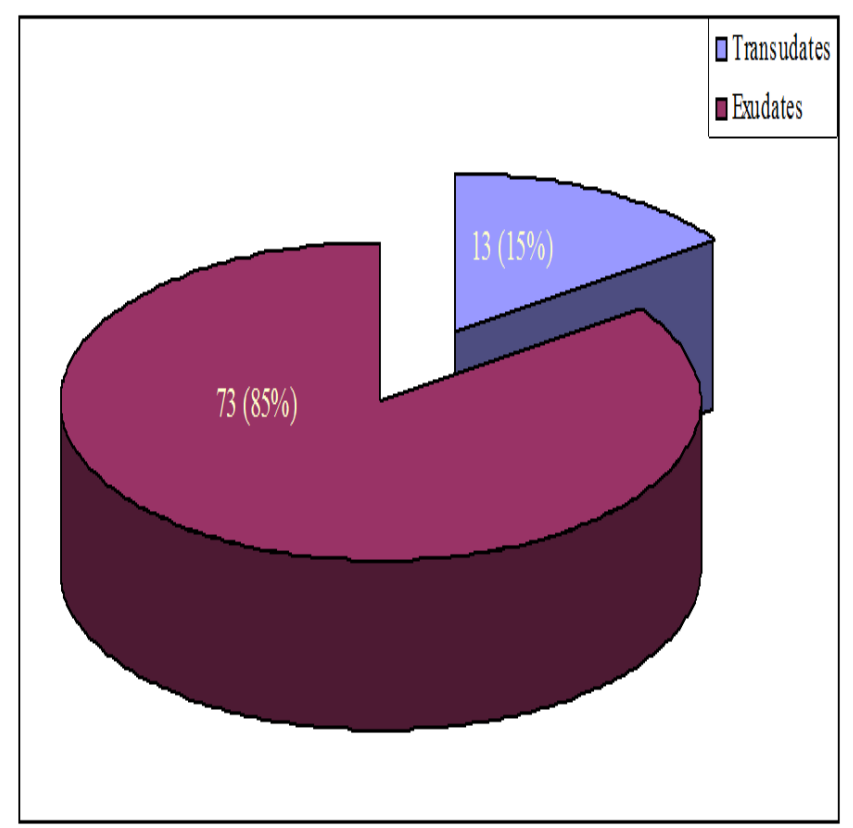

Figure 1:

\section{DISCUSSION}

Pleural effusions occur in different diseases: Transudative pleural effusions like Congestive heart failure, Cirrhosis of liver, Pulmonary embolization, Nephrotic syndrome, Peritoneal dialysis, Superior vena cava obstruction, Myxedema, Urinothorax and Exudative pleural effusions in Neoplastic diseaseMetastatic disease Mesothelioma, Infectious

diseases, Pulmonary embolization, Gastrointestinal disease, Esophageal perforation, Pancreatic disease, Intraabdominal abscesses, Diaphragmatic hernia, after abdominal surgery, Endoscopic variceal sclerotherapy, after liver transplant, Collagen vascular diseases,

Rheumatoid pleuritis, Systemic lupus erythematosus, Drug-induced lupus, Immunoblastic lymphadenopathy, Sjögren's syndrome, Granulomatosis with polyangiitis, Churg-Strauss syndrome, Post-coronary artery bypass surgery, Asbestos exposure, Sarcoidosis, Uremia, Meigs' syndrome, Yellow nail syndrome, Drug-induced pleural diseases. (Nitrofurantoin, Dantrolene, Methysergide, Bromocriptine, Procarbazin, Amiodarone), Trapped lung, Radiation therapy, Post-cardiac injury syndrome, Hemothorax, Iatrogenic injury, Ovarian hyperstimulation syndrome, Pericardial disease, Chylothorax [1]. The clinical features play an important role in identifying the pathogenesis, the first step in proper and adequate diagnosis of pleural effusion is correctly classifying it into exudative and transudative types by analysis of the pleural fluid for appropriate management. The sample size of this study was 86 which is comparable to 73 Perlat Kapisyzi et al[9]., 100 patients of Hoda Abu Youssef et al[10]. 148 of U. Yilmaz Toray et al[11]. 72 of Castano Vdriales JL et al[8]. The incidence of exudates in our study was 74 and 12 were transudates. The transudates were fewer in numbers in other studies as well. Castano V driales JL et al[8] had 17 transudates, Perlat Kapisyzi et al had 18, and Porcel[12] which were as similar as in this study.

This study mostly involved cases of pleural effusion that were secondary to tubercular pleurisy 43 (50 \%)cases followed by malignancy 17(19.8\%) cases, parapneumonic effusion 13 (15.1\%)cases, congestive heart failure $11(12.8 \%)$ cases and few cases of hepatic hydrothorax 1 (1.2\%) secondary to chronic liver disease and empyema thoracis 2(3\%). The frequency of tubercular pleural effusion was similar in study conducted by Dhital K R and co workers ${ }^{13}$ done in Kathmandu, Nepal from July 2010 to August 2011 where tubercular effusion was the most common pleural effusion in the study accounting 21 out of 62 cases (33.9\%), while Carcinoma lung was the second most common cause accounting for $14.5 \%$ (9), Similarly in a study done by Guleria et al[14]. in India, in 2003 involving 75 patients, 50 patients had exudative (25 tubercular and 25 non-tubercular) and 25 had transudative effusion. This distribution closely resembles the etiological distribution of pleural effusion of this study. Tuberculosis is very common in our part of the world with high prevalence. Although tuberculosis may present with a variety of symptoms and morphological presentations in the lung, this study mostly involved patients with tubercular pleurisy. In developed countries as shown in study by Storey and coworkers [15] at mayo clinic in a series of 133 patients reported that malignancy accounted for nearly 50 percent of patients with pleural effusion and that nearly one third of the patients with malignancy and effusion had lymphoma

The age distribution in this study showed that the minimum and maximum age of the study population was 17 and 88 years respectively with a range of 71 years. The mean age was 46 years with a standard distribution of 20.6 years. Most of the study population were between the age group of 15-25 years (19.76\%) representing the active working age group and $15.11 \%$ were $\geq 65$ years of age.

Out of 86 patients, 42 patients were male (48.8\%) and 44 female sex (51. 2\%). The number of female patients were slightly higher than male patients. The higher incidence of female patients as compared to males may be due to higher incidence of smoking, poor economic, sanitation and indoor activities. 43 patients were found to be smokers. Among the 43 smokers, 18(41.86\%) smokers 
were males and 25(58.13\%) smoker was from females. The number of smokers was comparatively high in females than in males. Using clinical diagnosis in this study the number of patients having exudative and transudative pleural effusion were 73 (85.04\%) and 13 (15\%) respectively. This is comparable with the most studies in pleural effusion were the number of exudates out proportion transudates by several folds $[1,2,4,5,16,17,18]$.

Using different parameters of Light's Criteria, the study showed that $74.41 \%$ (64), 90.69\% (78) and 70.94\% (61) of the pleural effusion were classified as exudate with pleural fluid $\mathrm{LDH}>2 / 3^{\text {rd }}$ of the serum level, pleural protein to serum protein ratio of $>0.5$ and pleural fluid to serum LDH ratio $>0.6$ respectively. These figures could possibly be due to high proportions of tubercular pleural effusion, which gives exudative characteristics on laboratory evaluation of the pleural fluid biochemical parameters. Pleural fluid LDH ratio and absolute pleural

correctly classified as exudates by the criteria of CRP level $>10 \mathrm{mg} / \mathrm{dl}$, which was set as a cut-off value for discrimination of exudates and transudates. While 8 samples were misclassified as transudates by this criterion. This criterion had a sensitivity values of $81.39 \%$ with a significant $p$ value of $<0$. 001.Among the 13 Parapneumonic effusion studied in this study, 12 (92.31\%) were classified correctly as exudates by the criteria of CRP level $>10 \mathrm{mg} / \mathrm{dl}$, which was set as a cutoff value for discrimination of exudates and transudate.

\section{CONCLUSION}

With classifying threshold of CRP $>10 \mathrm{mg} / \mathrm{dl}$ only 63 of 73 clinically defined exudates were correctly classified

\section{REFERENCES}

1. Kasper DL, Fauci AS, Longo DL, Braunwald E, Hauser SL, Jameson JL, eds. Harrison's Principles of Internal Medicine. 18th ed. New York, NY: McGrawHill; 2012:2178.

2. Noppen M. Normal volume and cellular contents of pleural fluid. Paediatric respiratory reviews. 2004;5 Suppl A:S201-3.

3. Sahn SA. State of the art. The pleura. The American review of respiratory disease. 1988;138 (1):184-234.

4. Broaddus VC, Light RW. What is the origin of pleural transudates and exudates? Chest. 1992;102 (3):658-9.

5. Light RW, Macgregor I, Luchsinger PC, Ball WC. Pleural effusions: the diagnostic separation of transudates and exudates. Ann Intern Med 1972; 77:50713. fluid LDH values correlated well with the clinical diagnosis in this study as compared to pleural fluid to serum protein ratio with better sensitivity, specificity and predictive values which is similar to the findings in the study by Hamal and coworkers [19].

Higher mean value for CRP level was found in parapneumonic effusion $33.91 \mathrm{mg} / \mathrm{dl}$ with the standard deviation of 10.02 and followed by $16.41 \mathrm{mg} / \mathrm{dl}$ in TB effusion with standard deviation 6.82. Lower mean value for CRP level was noted for CHF i.e, $9 \mathrm{mg} / \mathrm{dl}$ with standard deviation of 2.59. For exudates, mean value of CRP level was observed as $18.56 \mathrm{mg} / \mathrm{dl}$ with standard deviation 11.01. For the total 86 pleural effusions, the mean value of CRP level was found to be $16.68 \mathrm{mg} / \mathrm{dl}$ with standard deviation 11.54 and the mean CRP in transudates is less than $10 \mathrm{mg} / \mathrm{dl}$.

Out of 43 TB effusions fluid i.e. clinically defined exudates in this study, 35 (81.40\%) TB effusion were

as exudates and showed the sensitivity of $87.6 \%$ and misclassified 1 transudate as exudate. The result has almost similar sensitivity, specificity, positive predictive value and negative predictive value compared with Parameters of Light's criteria. Measurement of this single parameter can add better results in differentiating exudates from transudates as well for identifying parapneumonic effusions and identifying tubercular pleural effusion. CRP $>30 \mathrm{mg} / \mathrm{dl}$ showed better correlation in classifying exudates. However, larger population based multicenter studies needed to be done to reach a definitive conclusion.

Acknowledgements: We would like to extent our heartiest gratitude to Medical ward staffs and Medical record division, Bir Hospital

6. Daniil, Z.D., Zintzaras, E., Kiropoulos, T., Papaloannou, A.I., Koutsokera, A., Kastanis, A. et al, Discrimination of exudative pleural effusions based on multiple biological parameters. Eur Respir J. 2007; 30: 957-964. 6.

7. Iqbal M, Jaffery T, Shah SH. Isolated pleural fluid lactic dehydrogenase level: a cost effective way of characterizing pleural effusions. Journal of Ayub Medical College, Abbottabad: JAMC. 2002; 14 (2):2-5.

8. Castano Vidriales JL, Amores Antequera C. Use of pleural fluid C-reactive protein in laboratory diagnosis of pleural effusions. The European journal of medicine. 1992; 1(4):201-7.

9. Perlat Kapisyzi, Dhimiter Argjiiri, Genc Bgrazeri et al.Use of pleural fluid C- reactive protein as a diagnostic marker for pleural effusion. Chest. 2009; 136.

10. Hoda- Abu-Yousef, Sherif A, Hassan A, Essam O. Value of C-reactive protein in etiologic diagnosis of 
pleural effusion. Egyptian Journal of bronchology 2010; 4(2): 124.

11. U. yilmaz Toray. Z. Yildiram et al. use of pleural fluid C-reactive protein in Diagnosis of pleural effusions. Respiratory medicine 2000; 94: 432.

12. Porcel JM, Vives M, Cao G, Bielsa S, Ruiz-Gonzalez A, Martinez-Iribarren A, et al. Biomarkers of infection for the differential diagnosis of pleural effusions. The European respiratory journal. 2009;34 (6):1383-9.

13. Dhital KR, Acharya R, Bhandari R, Kharel P, Giri KP, Tamrakar R. Clinical profile of patients with pleural effusion admitted to KMCTH. Kathmandu University medical journal (KUMJ). 2009;7(28):438-44.

14. Guleria R, Agarwal SR, Sinha S, Pande JN, Misra A. Role of pleural fluid cholesterol in differentiating transudative from exudative pleural effusion. The National medical journal of India. 20031:6 (2):64-9.
15. Storey DD, Dines DE, Coles DT. Pleural effusion. A diagnostic dilemma. Jama. 1976;236(19):2183-6.

16. Garcia EP, Pallida IN, Shum C. Mesothelioma, adenosine deaminase and $\mathrm{C}$ - reactive protein. Arch Bronconeumol 2005; 41(3): 175.

17. Z.D. Daniil, E. Zintzaras et al. Discrimination of exudative pleural effusions based on multiple biological parameters. European Respiratory Journal 2007;30: 957.

18. Saeed Alinejad Moallem et al. Follow Up \& Differential Diagnostic Of Changes of C-Reactive Protein Concentration \& adenosine Deaminase Activity In Patients With Tuberculous Pleurisy. Asian Journal Of Biochemical And Pharmaceutical Research 2012;4:3.

19. A. B. Hamal, K. N. Yogi, N. Bam, S. K. Das, and R. Karn. Pleural Fluid Cholesterol in Differentiating Exudative and Transudative Pleural Effusion. Pulmonary Medicine.Volume 2013 (2013), Article ID 135036, 4.

\section{Article History:}

Received: 2 January, 2017

Accepted: 17 January, 2017

Published online: 25 February, 2017

\section{For Citation:}

Thapa J et al. Use of Pleural Fluid C- Reactive Protein and comparison with Light's criteria to differentiate Exudative from Transudative Pleural Effusions in Nepalese population. International Journal of Medicine \& Biomedical Sciences. 2016; 2(1):6-12 